\title{
Hubungan Kejadian Post Dural Puncture Headache (PDPH) pada Pasien Sectio Caesarea dengan Anestesi Spinal di Rumah Sakit M Tahun 2019
}

\author{
Resiana Karnina ${ }^{*}$, Mutiara Putri ${ }^{2}$ \\ 1) Departemen Anestesi, Fakultas Kedokteran dan Kesehatan, Universitas Muhammadiyah Jakarta \\ 2) Fakultas Kedokteran dan Kesehatan, Universitas Muhammadiyah Jakarta \\ *Corresponding author: sublime_dr@yahoo.com
}

\begin{abstract}
Background: according to the data of Riset Kesehatan Dasar (Riskesdas) 2018, the process of childbirth of cesarean section in Indonesia reached $17.6 \%$ of all total births. Sectio caesarea in Indonesia has increased and will increase use of spinal anesthesia that has complications of Post Dural Puncture Headache (PDPH). Purposes: to determine the relationship between Post Dural Puncture Headache (PDPH) and age, nutritional status, and PDPH history of patients sectio cesarean with spinal anesthesia at M Hospital. Methods: this research used cross sectional method and chi square test. The sample in this study were patients who sectio caesarea with spinal anesthesia at M Hospital in June - November 2019 with 125 samples. Results: obtained $2(1.6 \%)$ patients who experienced PDPH events. All PDPH events occur in adulthood (26 - 45 years) with normal nutritional status and don't have a history of PDPH. The analysis results there is no relationship between PDPH and age $(p=0.415)$, and there is no relationship between PDPH and nutritional status $(p=0.924)$. Conclusion: there is no relationship between Post Dural Puncture Headache (PDPH) to age, and nutritional status of patients sectio caesarea with spinal anesthesia at M Hospital in June - November 2019.
\end{abstract}

Keywords: Spinal Anesthesia, PDPH, Sectio Caesarea

\begin{abstract}
ABSTRAK
Latar belakang: menurut data Riset Kesehatan Dasar (Riskesdas) tahun 2018, proses persalinan dengan operasi caesar di Indonesia mencapai 17,6\% dari seluruh total kelahiran. Persalinan melalui sectio caesarea di Indonesia mengalami peningkatan dan akan mengakibatkan peningkatan penggunaan anestesi spinal yang memiliki komplikasi berupa Post Dural Puncture Headache (PDPH). Tujuan: untuk mengetahui hubungan kejadian Post Dural Puncture Headache (PDPH) terhadap usia, status gizi, dan riwayat PDPH pasien yang menjalani sectio caesarea dengan anestesi spinal di Rumah Sakit M. Metode: penelitian ini menggunakan metode cross sectional serta uji chi square. Sampel pada penelitian ini adalah pasien yang menjalani sectio caesarea dengan anestesi spinal di Rumah Sakit M pada bulan Juni - November 2019 dengan jumlah 125 sampel. Hasil: didapatkan 2(1,6\%) pasien yang mengalami kejadian PDPH. Seluruh kejadian PDPH terjadi pada usia dewasa (26- 45 tahun) dengan status gizi normal dan tidak memiliki riwayat PDPH. Pada hasil analisis didapatkan tidak terdapat hubungan antara kejadian PDPH terhadap usia $(\mathrm{p}=0,415)$ dan tidak terdapat hubungan antara kejadian PDPH terhadap status gizi $(\mathrm{p}=0,924)$. Kesimpulan: tidak terdapat hubungan antara kejadian Post Dural Puncture Headache (PDPH) terhadap usia dan status gizi
\end{abstract}


pasien yang menjalani sectio caesarea dengan anestesi spinal di Rumah Sakit M pada bulan Juni - November 2019.

Kata kunci: Anestesi Spinal, PDPH, Sectio Caesarea

\section{PENDAHULUAN}

Persalinan melalui sectio caesarea di Indonesia mengalami peningkatan. Menurut data Riset Kesehatan Dasar (Riskesdas) tahun 2018, proses persalinan dengan cara operasi caesar di Indonesia mencapai $17,6 \%$ dari seluruh total kelahiran. Provinsi DKI Jakarta menempati urutan pertama sebesar $31,1 \%$ diikuti provinsi Bali 30,2\% dan Sumatera Utara $23,9 \%$ (1). Terlihat peningkatan dari tahun 2013 yang menunjukkan bahwa persalinan melalui operasi caesar di Indonesia sebesar 9,8\% (2).

Anestesi spinal dipilih sebagai salah satu cara menghilangkan rasa sakit pada operasi caesar. Namun, anestesi spinal juga menimbulkan beberapa komplikasi salah satunya adalah Post Dural Puncture Headache (PDPH) yang memiliki gejala nyeri kepala yang pada umumnya mengenai daerah frontal dan occipital (3).

Di Inggris, Insiden dural puncture atau penusukan pada dura dalam praktik obstetri adalah $0,18-3,6 \%$ dengan $80 \%$ dari pasien tersebut menderita Post Dural Puncture Headache (PDPH) (4). Penelitian lain yang dilakukan pada tahun 2015 sampai 2016 di rumah sakit rujukan Felege Hiwot, North West Ethiopia menunjukkan dari 251 pasien yang termasuk dalam penelitian tersebut, 107 pasien $(42,6 \%)$ menderita Post Dural Puncture Headache (PDPH), dan dalam penelitian tersebut, tidak ditemukan hubungan antara kejadian Post Dural Puncture Headache (PDPH) terhadap usia, Body Mass Index (BMI), dan riwayat PDPH sebelumnya (5).
Tahun 2013 di Rumah Sakit Dr. Hasan Sadikin Bandung, dengan subjek penelitian sebanyak 115 wanita hamil, ditemukan bahwa sebagian besar kejadian Post Dural Puncture Headache (PDPH) ditemukan paling banyak pada usia $25-30$ tahun sebanyak 14 pasien dari 22 pasien yang positif mengalami Post Dural Puncture Headache (PDPH) (6).

Pada tahun yang berbeda di lokasi yang sama, tahun 2015 di Rumah Sakit Dr. Hasan Sadikin Bandung dilakukan penelitian mengenai insiden Post Dural Puncture Headache (PDPH) setelah anestesi spinal, didapatkan dari 156 subjek yang mengikuti penelitian, terdapat 10 subjek (6,4\%) mengalami Post Dural Puncture Headache (PDPH) (7).

Artikel ini disusun penulis, berkaitan dengan pernyataan diatas yakni terlihat adanya peningkatan persalinan melalui operasi caesar dan hal tersebut akan mengakibatkan peningkatan penggunaan anestesi spinal yang memiliki komplikasi berupa Post Dural Puncture Headache (PDPH).

\section{METODE}

Penelitian ini menggunakan metode penelitian kuantitatif. Studi cross sectional merupakan desain yang digunakan dalam penelitian ini, data yang digunakan berupa data sekunder yang berasal dari data rekam medis pasien yang menjalani sectio caesarea dengan anestesi spinal di Rumah Sakit M pada bulan Juni sampai dengan November 2019. Data diolah menggunakan program statistik SPSS dengan uji chi 
square (p-value $<0,05$ dianggap signifikan) serta uji normalitas menggunakan uji kolmogorov-smirnov.

Populasi dalam penelitian ini adalah seluruh pasien yang menjalani sectio caesarea dengan anestesi spinal di Rumah Sakit M pada bulan Juni sampai dengan November 2019. Teknik pengambilan sampel menggunakan total sampling yaitu jumlah sampel yang diambil sama dengan jumlah populasi yang ada. Maka, setiap pasien yang telah menjalani tindakan sectio caesarea dengan anestesi spinal dimasukkan dalam penelitian sesuai dengan periode yang telah ditetapkan serta berdasarkan kriteria inklusi dan eksklusi.

Kriteria inklusi penelitian ini adalah semua pasien yang menjalani sectio caesarea dengan anestesi spinal di Rumah Sakit M pada bulan Juni - November 2019. Sedangkan kriteria eksklusi adalah pasien dengan data rekam medis tidak lengkap. Variabel independen yang digunakan pada penelitian ini adalah usia, status gizi dan riwayat PDPH, sedangkan variabel dependen adalah kejadian Post Dural Puncture Headache (PDPH).

Penelitian ini telah mendapatkan surat persetujuan dari Komisi Etik Penelitian Kesehatan Fakultas Kedokteran dan Kesehatan Universitas Muhammadiyah Jakarta dengan nomor 119/A/PE/KE/FKK$\mathrm{UMJ} / \mathrm{XII} / 2019$.

\section{HASIL}

Berdasarkan tabel 1 diketahui bahwa dari 125 sampel yang menjalani sectio caesarea dengan anestesi spinal di Rumah Sakit M pada bulan Juni - November 2019, dewasa awal (26 - 35 tahun) menjadi usia yang paling banyak yaitu sebesar 83 orang $(66,4 \%)$. Pada karakteristik status gizi, sebagian besar sampel ada pada status gizi normal sebesar $72 \%$, obesitas sebesar $28 \%$ dan tidak ditemukan dengan status gizi kurang.

Tabel 1. Karakteristik Pasien Sectio Caesarea dengan Anestesi Spinal di RS M pada Bulan Juni - November 2019

\begin{tabular}{lcc}
\hline \multicolumn{1}{c}{ Karakteristik } & $\begin{array}{c}\text { Jumlah } \\
(\mathbf{n})\end{array}$ & $\begin{array}{c}\text { Persentase } \\
(\%)\end{array}$ \\
\hline Usia & & \\
$17-25$ tahun & 21 & 16,8 \\
$26-35$ tahun & 83 & 66,4 \\
$36-45$ tahun & 21 & 16,8 \\
Status Gizi & & \\
Kurang & 0 & 0 \\
Normal & 90 & $72 \%$ \\
Obesitas & 35 & $28 \%$ \\
Riwayat PDPH & & \\
Ada & 0 & 0 \\
Tidak Ada & 125 & $100 \%$ \\
Kejadian PDPH & & \\
Ya & 2 & 1,6 \\
Tidak & 123 & 98,4 \\
\hline
\end{tabular}

Seluruh sampel yang menjalani sectio caesarea dengan anestesi spinal di RS M pada bulan Juni - November 2019 tidak memiliki riwayat Post Dural Puncture Headache (PDPH). Dari 125 sampel, ditemukan bahwa yang mengalami kejadian Post Dural Puncture Headache (PDPH) setelah menjalani sectio caesarea dengan anestesi spinal di Rumah Sakit M pada bulan Juni - November 2019 sebanyak 2 orang $(1,6 \%)$.

Tabel 2 menunjukkan bahwa PDPH terjadi pada responden dengan usia $26-35$ tahun dan 36 - 45 tahun. Sebagian besar terjadi pada status gizi normal dan terjadi pada responden yang justru tidak memiliki riwayat PDPH. Hasil uji bivariat pada Tabel 3 menunjukkan bahwa tidak ada hubungan yang signifikan antara PDPH dengan usia (pvalue $=0,415)$ dan status gizi (pvalue $=0,924)$. 
Tabel 2. Kejadian Post Dural Puncture Headache (PDPH) berdasarkan Usia, Status Gizi dan Riwayat PDPH

\begin{tabular}{lcc}
\hline \multirow{2}{*}{ Karakteristik } & \multicolumn{2}{c}{ Kejadian PDPH } \\
\cline { 2 - 3 } & Ya & Tidak \\
\hline Usia & & \\
$17-25$ tahun & 0 & 21 \\
$26-35$ tahun & 1 & 82 \\
$36-45$ tahun & 1 & 20 \\
Status Gizi & & \\
Kurang & 0 & 0 \\
Normal & 2 & 88 \\
Obesitas & 0 & 35 \\
Riwayat PDPH & & \\
Ada & 0 & 0 \\
Tidak Ada & 2 & 123 \\
\hline
\end{tabular}

Tabel 3. Hubungan Kejadian Post Dural Puncture Headache (PDPH) Terhadap Usia dan Status Gizi Pasien yang Menjalani Sectio Caesarea dengan Anestesi Spinal di RS M pada Bulan Juni - November 2019

\begin{tabular}{|c|c|c|c|c|c|}
\hline \multirow{2}{*}{ Karakteristik } & \multicolumn{4}{|c|}{ Kejadian PDPH } & \multirow{2}{*}{ Pvalue* } \\
\hline & Ya & $\%$ & Tidak & $\%$ & \\
\hline \multicolumn{6}{|l|}{ Usia } \\
\hline $17-25$ & 0 & 0 & 21 & 100 & \multirow{3}{*}{0,415} \\
\hline $26-35$ & 1 & 1,2 & 82 & 98,8 & \\
\hline $36-45$ & 1 & 4,8 & 20 & 95,2 & \\
\hline \multicolumn{6}{|l|}{ Status Gizi } \\
\hline Normal & 2 & 2,2 & 88 & 97,8 & \multirow{2}{*}{0,924} \\
\hline Obesitas & 0 & 0 & 35 & 100 & \\
\hline
\end{tabular}

\section{PEMBAHASAN}

Berdasarkan tabel 2 diketahui bahwa semua kejadian Post Dural Puncture Headache (PDPH) terjadi pada subjek yang tidak memiliki riwayat PDPH dan dengan status gizi normal sebanyak 2 sampel. Kejadian Post Dural Puncture Headache (PDPH) terdapat pada sampel yang berusia dewasa awal (26 - 35 tahun) sebanyak 1 dari 2 sampel, dan pada usia dewasa akhir (36 45 tahun) sebanyak 1 dari 2 sampel. Hal ini sejalan dengan hasil penelitian lain yang menemukan bahwa kejadian PDPH paling banyak terjadi pada umur 25 - 30 tahun (6).

Penelitian di Semarang pada tahun 2018 menunjukkan kejadian Post Dural Puncture Headache (PDPH) sebesar 59,4\% dari 32 pasien yang dijadikan sampel dalam penelitian (8). Penelitian lain yang dilakukan pada bulan September 2015 sampai Januari 2016 di rumah sakit rujukan Felege Hiwot, North West Ethiopia menunjukkan dari 251 pasien yang termasuk dalam penelitian tersebut, 107 pasien $(42,6 \%)$ menderita Post Dural Puncture Headache (PDPH) (5).

Sedikitnya angka kejadian Post Dural Puncture Headache (PDPH) pada penelitian ini dapat disebabkan karena adanya faktor lain seperti penggunaan ukuran dan bentuk jarum yang sudah tepat, karena penggunaan jarum yang tepat mampu menurunkan kejadian Post Dural Puncture Headache (PDPH). Penelitian yang dilakukan pada tahun 2017 menunjukkan bahwa pasien yang mendapatkan anestesi spinal dengan jarum yang besar memiliki 8 kali lebih mungkin mengalami kejadian Post Dural Puncture Headache (PDPH) dibanding pada pasien yang mendapatkan anestesi dengan menggunakan ukuran jarum yang kecil (5).

Hasil analisis hubungan antara kejadian Post Dural Puncture Headache (PDPH) terhadap usia pasien yang menjalani sectio caesarea dengan anestesi spinal di Rumah Sakit M pada bulan Juni November 2019 diperoleh hasil yaitu pada terdapat $1,2 \%$ yang mengalami kejadian PDPH dari 83 sampel yang berusia 26 - 35 tahun, sedangkan pada usia 36 - 45 tahun terdapat $4,8 \%$ yang mengalami kejadian PDPH dari 21 sampel pada usia tersebut.

Hasil pada penelitian ini sejalan dengan penelitian lainnya yaitu penelitian di Rumah Sakit Hasan Sadikin Bandung 
dengan subjek penelitian sebanyak 115 wanita hamil yang telah melakukan sectio caesarea, ditemukan bahwa kejadian Post Dural Puncture Headache (PDPH) sebagian besar terjadi pada kelompok usia 25 - 30 tahun, sebanyak 14 dari 22 orang yang mengalami Post Dural Puncture Headache (PDPH) setelah melakukan sectio caesarea dengan anestesi spinal (6). Kejadian Post Dural Puncture Headache (PDPH) sering terjadi pada usia muda (1840 tahun). Kejadian PDPH jarang terjadi pada usia tua karena elastisitas struktur kranial pada orang tua sudah berkurang (9).

Namun, hasil analisis mengenai kejadian Post Dural Puncture Headache (PDPH) terhadap usia pasien yang menjalani sectio caesarea pada penelitian ini didapatkan hasil $\mathrm{p}$ value $=0,415$ ( $>0,05)$ yang artinya tidak terdapat hubungan antara kejadian Post Dural Puncture Headache (PDPH) terhadap usia pasien yang menjalani sectio caesarea dengan anestesi spinal di Rumah Sakit M pada bulan Juni - November 2019. Hasil penelitian tersebut sejalan dengan penelitian sebelumnya, yang dilakukan pada tahun 2017 yaitu tidak ditemukan hubungan antara kejadian Post Dural Puncture Headache (PDPH) dengan usia (5).

Hasil analisis hubungan antara kejadian Post Dural Puncture Headache (PDPH) terhadap status gizi pasien yang menjalani sectio caesarea dengan anestesi spinal di Rumah Sakit M pada bulan Juni November 2019 diperoleh hasil yaitu pada sampel yang memiliki status gizi normal terdapat 2,2\% yang mengalami kejadian PDPH, sedangkan pada sampel yang memiliki status gizi obesitas tidak terdapat kejadian PDPH.

Pada penelitian ini terdapat 90 sampel (72\%) memiliki status gizi normal dan 35 sampel (28\%) memiliki status gizi obesitas, dan hasil analisis mengenai hubungan kejadian Post Dural Puncture Headache (PDPH) terhadap status gizi pasien yang menjalani sectio caesarea di Rumah Sakit M pada bulan Juni - November 2019 menunjukkan hasil $\mathrm{p}$ value $=0,924$ $(\mathrm{p}>0.05)$ yang artinya tidak terdapat hubungan antara kejadian Post Dural Puncture Headache (PDPH) terhadap status gizi pasien yang menjalani sectio caesarea dengan anestesi spinal di Rumah Sakit M pada Bulan Juni - November 2019. Kejadian Post Dural Puncture Headache (PDPH) berhubungan dengan rendahnya indeks massa tubuh, wanita yang obesitas memiliki kejadian Post Dural Puncture Headache (PDPH) yang lebih rendah. Belum diketahui mekanisme yang mendasari hubungan kejadian Post Dural Puncture Headache (PDPH) terhadap status gizi seseorang. Namun, lebih rendahnya kejadian Post Dural Puncture Headache (PDPH) pada wanita yang obesitas diduga terjadi karena adanya peningkatan tekanan intra-abdominal sehingga dapat bertindak sebagai pengikat abdomen yang membantu menutup terbukanya dura setelah dilakukan anestesi spinal dan mengurangi hilangnya cairan serebrospinal (CSS) (10).

\section{KESIMPULAN}

Berdasarkan hasil dan pembahasan diatas, maka dapat disimpulkan yaitu tidak terdapat hubungan antara kejadian Post Dural Puncture Headache (PDPH) terhadap usia dan status gizi pasien yang menjalani sectio caesarea dengan anestesi spinal di Rumah Sakit M pada bulan Juni November 2019. 


\section{UCAPAN TERIMAKASIH}

Penulis mengucapkan terima kasih kepada pihak atau lembaga yang membantu dalam penelitian ini, terutama untuk Fakultas Kedokteran dan Kesehatan Universitas Muhammadiyah Jakarta.

\section{KONFLIK KEPENTINGAN}

Penulis menyatakan tidak memiliki konflik kepentingan apa pun.

\section{REFERENSI}

1. Kementerian Kesehatan Republik Indonesia. Riset Kesehatan Dasar 2018. Badan Penelitian dan Pengembangan Kesehatan. Jakarta: Kementerian Kesehatan Republik Indonesia; 2018.

2. Kementerian Kesehatan Republik Indonesia. Riset Kesehatan Dasar 2013. Badan Penelitian dan Pengembangan Kesehatan. Jakarta: Kementerian Kesehatan Republik Indonesia; 2013.

3. Santoso AH, Ngurah IG, Sudadi. Management PDPH (Post Dural Puncture Headache) as a Neurologic Complication After Regional Anaesthesia. J Komplikasi Anestesi. 2015;2:63-74.

4. Chohan U, Hamdani GA. Post dural puncture headache. J Pakistan Med Assoc. 2003;53(8):359-67.

5. Tarekegn F, Eshetie S, Aregawi A, Moges K. Assessment of the Prevalence and Associated Risk Factors of Post Dural Puncture Headache (PDPH) after Cesarean Section Delivery under Spinal Anesthesia. J Anesth Crit Care Open Access. 2017;8(6):6-10.

6. Irawan D, Tavianto D, Surahman E. Kejadian Post Dural Puncture Headache dan Nilai Numeric Rating
Scale Pasca Seksio Sesarea dengan Anestesi Spinal. J Anestesi Perioper. 2013;1(3):183-8.

7. Suwarman, Sitanggang RH, Mayasari F, Yuwono SH. Incidence of Post Dural Puncture Headache (PDPH) after Spinal Anesthesia at Dr. Hasan Sadikin General Hospital Bandung in February-April 2015 Period. Maj Anest Dan Crit Care. 2017;33 No 2.

8. Pambayun GP, Sudirman, Taadi. Applying the number 27 pencil point needle model and green tea in preventing post dural puncture headache in patients of spinal anesthesia post cesarean section. 2018;35-7.

9. Jenkinson R. Post-dural Puncture Headache. Cham: Abd-Elsayed A Pain Springer; 2019. 261-265 p.

10. Bezov D, Lipton RB, Ashina S. Postdural puncture headache: Part i diagnosis, epidemiology, etiology, and pathophysiology. Headache. 2010;50(7):1144-52. 